\title{
Características de la infección por influenza tipo A en un contexto pandémico en un hospital de Nicaragua
}

Guillermo Porras-Cortés ${ }^{1}$, Erika Lawrence-Berroterán², Claudia Martínez-Rivas ${ }^{3}$, Violeta Sclafani-Vivas ${ }^{3}$, Manuel Balladares-Munguía ${ }^{3}$, Salvador Rizo-Centeno ${ }^{3}$

${ }^{1}$ Infectología - Hospital Metropolitano Vivian Pellas. Km. 9 3/4 crta. a Masaya, Managua, Nicaragua, 12345. Tel. (505) 8882-0094, Fax: (505) 2255-6901. Correo electrónico: memopo200@yahoo.com

${ }^{2}$ Epidemiología Hospitalaria - Hospital Metropolitano Vivian Pellas.

${ }^{3}$ Laboratorio Clínico - Hospital Metropolitano Vivian Pellas.

Recibido: julio de 2009 / Aceptado: agosto de 2009

Introducción: Este estudio describe las características de los casos de gripe tipo A en un contexto pandémico en pacientes que acudieron con enfermedad respiratoria aguda a un hospital de Nicaragua.

Método: Es un estudio descriptivo realizado en el Hospital Metropolitano Vivian Pellas en Nicaragua. Se realizó detección de antígeno del virus de la influenza tipo A por hisopado nasal, con confirmación del Ministerio de Salud de Nicaragua para el subtipo A (H1N1).

Resultados: Del 3 al 25 de junio de 2009, 732 pacientes fueron atendidos con enfermedad respiratoria aguda y se les realizó una prueba de detección de antígenos para influenza tipo A. En 134 (18.3\%) pacientes la detección de antígeno fue positiva y en 68 de ellos el Ministerio de Salud confirmó el subtipo A (H1N1). En 29.9\% de los pacientes se estableció un vínculo epidemiológico de contacto o historia de viaje a zona con casos identificados. Las manifestaciones clínicas más frecuentes fueron fiebre, tos, secreción nasal, malestar general, estornudos, dolor de garganta y cefalea.

Conclusión: En este grupo de pacientes con enfermedad respiratoria aguda, con características clínicas propias de la gripe, se observó un patrón de transmisión local más que de casos importados.

Palabras clave: influenza A(H1N1) / infección / Nicaragua 


\section{Introducción}

Desde mediados de abril de 2009 se han reportado casos de infección respiratoria aguda por un nuevo subtipo de virus de influenza A de origen porcino. En México, los primeros casos fueron documentados en un brote en el poblado de La Gloria en el Estado de Veracruz cuando el $60 \%$ de sus habitantes fueron afectados con una enfermedad respiratoria aguda. Por otro lado, en California (Estados Unidos) se presentaban dos niños con infección respiratoria producida por un virus de influenza A no tipificable en ese momento. Posteriormente se determinó que se trataba de un nuevo subtipo viral producto de un reordenamiento a partir de cepas de origen porcino, humano y aviar que ha sido denominado virus de influenza A (H1N1) de origen porcino (CDC, 2009; Fraser et al., 2009).

Hasta el 29 de junio de 2009 la Organización Mundial de la Salud (OMS) había reportado un total de 70,893 casos de gripe por influenza A (H1N1) en 112 países con un total de 311 defunciones (WHO, 2009). En Nicaragua, el Ministerio de Salud reportó un total de 288 casos hasta el día 29 de junio de 2009, sin defunción. Estos casos han sido atendidos tanto en el sector público (instituciones del Ministerio de Salud) como en el sector privado y de proveedores de salud del Instituto Nicaragüense de Seguridad Social. En estos últimos casos, el Ministerio de Salud realizaba una nueva toma de muestra de hisopado nasal para tratar de confirmar si se trataba de una infección por virus de influenza tipo A (H1N1).

Aunque los datos iniciales en México orientaban que se trataba de un virus con tasas de letalidad elevadas (4.9\% al inicio de la epidemia), el comportamiento posterior en la misma república mexicana, como en otros países, ha demostrado que se trata de un virus que mayoritariamente produce enfermedad leve, de tal manera que la tasa de letalidad actual a nivel mundial es de 0.43\% (Fraser et al., 2009; WHO, 2009).

En Nicaragua el primer caso de influenza con el nuevo subtipo viral A(H1N1) fue diagnosticado el 1 de junio de 2009. A partir de ese momento los reportes de casos se presentaron en diferentes sitios de la ciudad capital de Managua y posteriormente en ciudades del interior del país. Hasta la fecha de realización del presente estudio el Ministerio de Salud de Nicaragua no reporta fallecidos por influenza tipo A (H1N1).

El presente estudio tiene como objetivo describir las características epidemiológicas y clínicas más relevantes de los casos de gripe por influenza tipo A en un centro hospitalario de Nicaragua en el contexto de la actual pandemia, durante el período comprendido entre el 3 y el 25 de junio de 2009 .

\section{Material y método}

Lugar: El Hospital Metropolitano Vivian Pellas es un centro privado de atención médica ubicado en Managua, Nicaragua.

Población: Fueron considerados como base del estudio todos los pacientes que acudieron con datos de enfermedad respiratoria aguda y que se realizaron una prueba de detección de antígeno de influenza tipo A en frotis nasal ( $\mathrm{N}=732$ pacientes). Fueron considerados como 
pacientes con influenza tipo A, 134 pacientes en quienes la prueba resultó positiva para la detección del antígeno. El Ministerio de Salud realizó visita domiciliar a los pacientes para tomar muestras y procesar pruebas correspondientes para confirmar si se trataba del virus de influenza tipo A (H1N1) de origen porcino. Se logró constatar que en 68 pacientes fue confirmado dicho subtipo viral acorde a lo notificado por el Ministerio de Salud. No se posee aún la información sobre la confirmación o no de los 66 pacientes restantes en quienes se había establecido un diagnóstico de influeza tipo A. Dado que para las fechas del estudio el Ministerio de Salud no reportaba ningún otro tipo de virus de influenza tipo A circulando en su sistema de vigilancia, los casos positivos para influenza tipo A pudieran tratarse del subtipo H1N1 de origen porcino.

Enfermedad respiratoria aguda fue definida como el inicio reciente (1 a 7 días) de al menos dos de los siguientes criterios: fiebre mayor o igual a $37.8^{\circ} \mathrm{C}$, dolor de garganta, tos, rinorrea o congestión nasal. Cuando un paciente tenía criterios definitorios de enfermedad respiratoria aguda era enviado al laboratorio clínico del hospital para la respectiva toma de muestra nasal. Los pacientes fueron referidos por sus respectivos médicos tratantes desde las áreas de consulta externa, hospitalización o sala de emergencia.

Período de estudio: El período de realización del estudio fue entre el 3 de junio de 2009 (fecha en que se implementó de manera estandarizada la realización de prueba de detección de antígeno de la influenza en el hospital), hasta el 25 de junio de 2009 (fecha en que se realizó un corte para análisis de los datos recolectados para fines de la presente publicación).

Prueba de laboratorio realizada: La muestra fue tomada por medio de un hisopo que se introducía por ambas fosas nasales y se profundizaba dentro de la nariz frotando sutilmente la mucosa nasal. Posteriormente se procesaba con la prueba de detección de antígeno de Influenza SD Bio Line Influenza Antigen (Standard Diagnostics, Inc), que puede detectar antígenos de influenza tipo A y tipo B. Las pruebas confirmatorias fueron realizadas por el Ministerio de Salud de Nicaragua de acuerdo a sus métodos estandarizados para influenza tipo A (H1N1).

Recolección de datos: Los datos demográficos, epidemiológicos y clínicos fueron recolectados a través del formato único de vigilancia de casos de influenza establecido por el Ministerio de Salud de Nicaragua.

\section{Resultados}

Entre el 3 y el 25 de junio de 2009, un total de 732 pacientes con enfermedad respiratoria aguda fueron atendidos en los servicios de consulta externa, emergencia u hospitalización en el Hospital Metropolitano, a quienes se les realizó una prueba de detección de antígeno de influenza tipo A. De estos 732 pacientes, en 134 (18.3\%) la detección de antígeno fue positiva para influenza tipo A. De estos 134 pacientes, 69 (51.5\%) eran varones y 65 (48.5\%) mujeres. El promedio de edad fue de 17.3 años. Sólo 10 de los pacientes ameritaron hospitalización. La duración promedio de hospitalización fue de 2.3 días (ver cuadro 1). Ningún paciente, durante el período de estudio, ameritó ingreso a unidad de cuidados intensivos. No se reportaron muertes. 
Cuadro 1. Características demográficas y epidemiológicas de 134 pacientes con infección por influenza A en Hospital Metropolitano, Nicaragua (3 de junio de 2009 - 25 de junio de 2009)

\begin{tabular}{l|l}
\multicolumn{1}{c|}{ Edad en años (media $\pm \mathrm{DE})$} & \multicolumn{1}{|c}{$17.3 \pm 7.4$} \\
\hline $\begin{array}{l}\text { Género } \\
\text { Masculino }\end{array}$ & $\begin{array}{l}69 / 134(51.5 \%) \\
65 / 134(48.4 \%)\end{array}$ \\
Femenino & $10 / 134(7.5 \%)$ \\
\hline Pacientes hospitalizados & $2.3 \pm 1.1$ \\
\hline Días de hospitalización (media $\pm \mathrm{DE})$ & $127 / 134(94.8 \%)$ \\
\hline Pacientes con información clínica y epidemiológica completa & 68 \\
\hline Pacientes confirmados para subtipo de influenza A (H1N1) & $38 / 127(29.9 \%)$ \\
\hline Pacientes con algún vínculo epidemiológico & $35 / 38$ \\
Contacto con otro enfermo respiratorio & $3 / 38$
\end{tabular}

De los 134 pacientes con influenza tipo, A sólo se ha confirmado el subtipo viral A (H1N1) de origen porcino en 68 (50.7\%) pacientes, el resto está aún pendiente de confirmación o la información no ha sido proporcionada por el Ministerio de Salud. El primer caso fue identificado el 3 de junio de 2009 y la mayor cantidad de casos (14) fueron diagnosticados el 17 de junio de 2009 (ver ilustración 1).

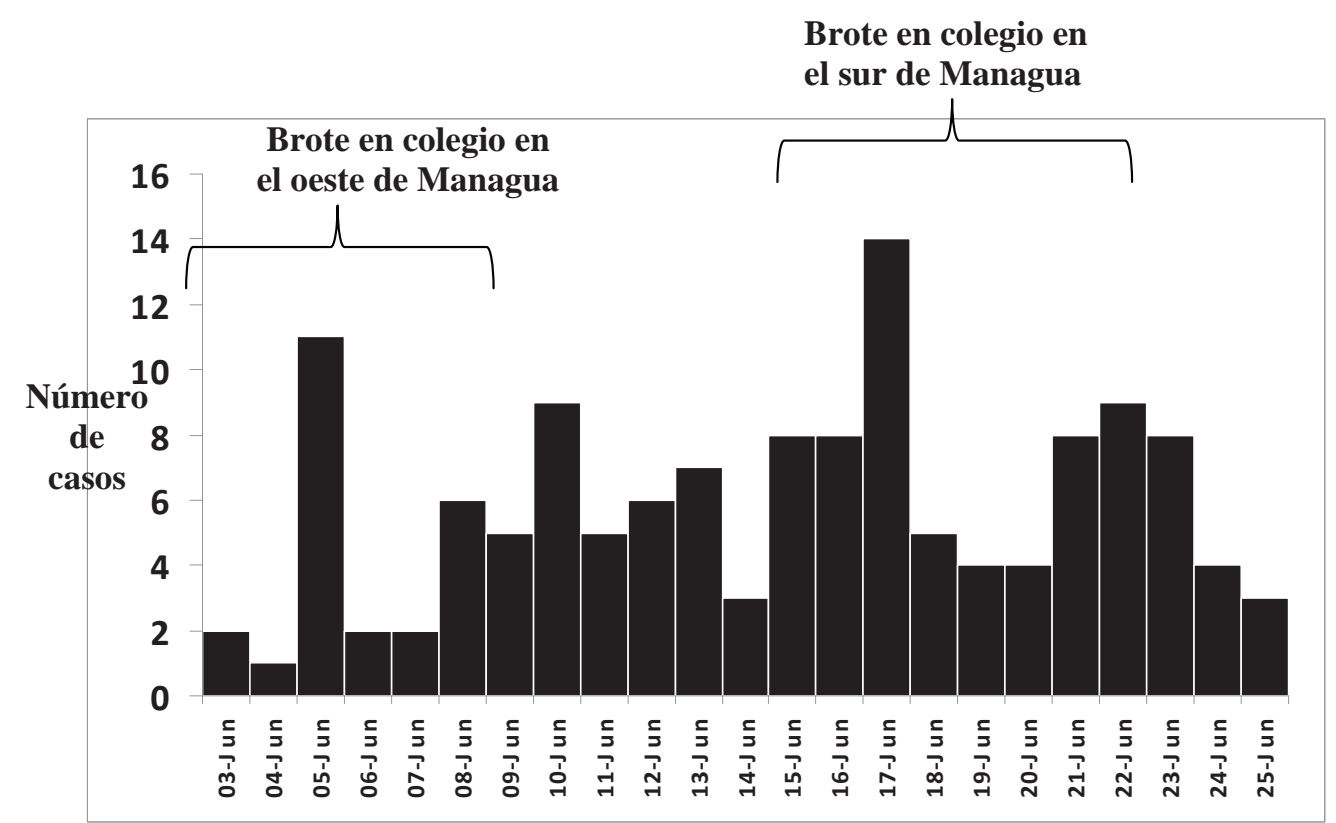

Ilustración 1. Curva epidemiológica de casos de influenza A en Hospital Metropolitano, Nicaragua (3 de junio de 2009 - 25 de junio de 2009) 
De los 134 pacientes con influenza tipo A, siete no fueron incluidos en el análisis final dado que no se tenían los datos clínicos y epidemiológicos completos. Por ende, el análisis de las características epidemiológicas y clínicas de los pacientes fue realizado en base a 127 pacientes de quienes se contaba con información completa. Entre las características epidemiológicas se encontró que en 38 pacientes (29.9\%) se logró establecer algún vínculo epidemiológico (cuadro 1). Este vínculo era el contacto con otra persona con enfermedad respiratoria (35 pacientes) y haber realizado un viaje en los últimos siete días a algún país que estuviera reportando casos de influenza A (H1N1) (3 pacientes).

Sólo cuatro pacientes tenían antecedentes de haber recibido vacunación contra influenza estacional en el último año.

Cinco pacientes tenían alguna condición clínica subyacente como asma bronquial (2), diabetes (1), rinitis alérgica (1), hipertensión arterial (1) y nefrectomía (1).

Las manifestaciones clínicas más frecuentes fueron: fiebre (97.0\%), tos (94.7\%), secreción nasal (94.1\%), malestar general (91.1\%), estornudos (88.2\%), dolor de garganta (70.6\%), cefalea (64.7\%) y dolor osteomuscular generalizado (58.8\%) (ver cuadro 2$)$.

Cuadro 2. Manifestaciones clínicas en 127 pacientes con infección por influenza A en el Hospital Metropolitano, Nicaragua (3 de junio de 2009 - 25 de junio de 2009)

\begin{tabular}{|l|c|}
\hline \multicolumn{1}{|c|}{ Manifestaciones clínicas } & N= 127 (\%) \\
\hline Fiebre & 97.0 \\
\hline Tos & 94.7 \\
\hline Secreción nasal & 94.1 \\
\hline Malestar general & 91.1 \\
\hline Estornudos & 88.2 \\
\hline Dolor de garganta & 70.6 \\
\hline Cefalea & 64.7 \\
\hline Dolor osteomuscular generalizado & 58.8 \\
\hline Conjuntivitis & 29.4 \\
\hline Náusea/vómito & 26.5 \\
\hline Disnea & 22.5 \\
\hline Dolor abdominal & 14.7 \\
\hline Diarrea & 5.9 \\
\hline Exantema & 2.9 \\
\hline
\end{tabular}

$\mathrm{Al}$ realizar el análisis epidemiológico se pudo detectar que 16 casos, de 24 detectados entre el 3 y el 8 de junio, correspondieron a un brote en un colegio en el sector oeste de la ciudad de Managua. Igualmente se pudo observar un segundo brote, con 21 casos de 41 registrados 
entre el 14 y el 20 de junio, en un colegio ubicado en el sector sur de la ciudad de Managua (ver ilustración 1).

\section{Discusión}

En este artículo se describen las características de pacientes con infección por influenza tipo A en un contexto de pandemia por un nuevo subtipo viral (H1N1) de origen porcino. Aunque no poseemos acceso a todos los resultados de laboratorio para confirmación de infección por el nuevo virus de influenza A (H1N1), consideramos que los casos de enfermedad respiratoria compatibles con influenza y con una prueba de detección de antígeno positiva para influenza tipo A, deben ser considerados eventualmente como causados por el nuevo virus que está produciendo la pandemia. Esta inferencia es atribuible dado que hasta la fecha de corte del estudio no hay reporte oficial por parte del Ministerio de Salud de que esté circulando ningún otro subtipo viral de influenza en Nicaragua durante el período del estudio. Una vez que se detecte un subtipo viral diferente producto del comportamiento estacional, tal inferencia dejaría de ser válida. No se logró constatar en casi la mitad de los casos (66 pacientes) el estatus de confirmación o no para el subtipo viral A (H1N1) dado que el Ministerio de Salud no proporcionó los datos.

Algunas características de los pacientes aquí presentados son comunes a los reportes de otros países. Se trata de una enfermedad que está afectando frecuentemente a niños y adolescentes (Novel Swine-Origin Influenza A (H1N1) Virus Investigation Team, 2009). Previamente se ha establecido que la edad de mayor afectación de influenza estacional en Nicaragua son los niños entre los dos y cinco años de edad, y que la incidencia disminuye por cada incremento de un año en la edad de los niños (Gordon et al., 2009). En la actual pandemia de influenza parece ser que la mayor incidencia está siendo reportada en niños mayores de cinco años o adolescentes.

La mayoría de los casos se han presentado con manifestaciones leves y sólo 7.5\% fueron hospitalizados brevemente. Esta tasa de hospitalización es menor a la reportada en Estados Unidos (9\%) y ligeramente superior a la presentada en México (6\%) (CDC, 2009).

En 29.9\% de los pacientes se logró establecer un vínculo epidemiológico, que fue muy frecuentemente el contacto con otra persona enferma. Sólo en tres pacientes se documentó un viaje reciente a áreas fuera del país que están reportando casos de influenza. Este dato refleja un comportamiento de transmisión local más que dependiente de casos foráneos, lo que sugiere que el historial de viaje fuera del país perdería validez epidemiológica. Se podría inferir incluso, dada la proporción de casos sin historial de viaje o contacto con alguien que ha realizado un viaje recientemente, que muy probablemente existía una subdetección de casos en algún período de tiempo previo a que la influenza de tipo pandémica fuera detectada en Nicaragua. En los reportes de otros países se ha demostrado mayoritariamente un patrón de casos importados, lo que ha contribuido a la diseminación de la enfermedad a nivel mundial (Liang, et al., 2009; Mossad, 2009).

La mayoría de los casos en el período del estudio se reportan a mediados de junio, sin embargo la curva epidemiológica no es muy característica de un brote dado que se distorsiona 
al inicio cuando el día 5 de junio se detectaron 11 pacientes. En el período circundante a dicha fecha la mayoría de los pacientes correspondían a una acumulación de casos de un mismo colegio localizado en el sector este de la ciudad de Managua. Igualmente, la mayoría de casos de los días 15 al 17 de junio corresponden a otro brote de casos en otro colegio entre estudiantes que asistieron a un acto de graduación. Éste último colegio está ubicado en el sector sur de la ciudad capital. Está bien reconocido entre las medidas de control de influenza pandémica el distanciamiento social y la clausura de centros educativos en donde se registre una acumulación de casos. El primer colegio al que se hace referencia en este estudio fue clausurado por un espacio de diez días, lo que seguramente contribuyó a que no se presentaran más casos en dicho centro. El segundo colegio referido aquí no fue clausurado dado que los casos se presentaron en la última actividad del ciclo escolar (graduación de estudiantes).

Las dos manifestaciones clínicas más frecuentes fueron la fiebre y la tos. A diferencia del informe de casos en Estados Unidos, Canadá y el Reino Unido, en donde reportan la presencia de diarrea entre el 23\% y 28\% de los pacientes, ésta fue encontrada sólo en el 5.9\% de los pacientes en el presente estudio (Novel Swine-Origin Influenza A (H1N1) Virus Investigation Team, 2009; WHO, 2009). En el informe inicial de México la disnea fue reportada en 79\% de los pacientes, aparentando ser desproporcionadamente elevado contra sólo el $22.5 \%$ de los casos descritos aquí, cifra más parecida al 14\% descrito en los casos de Canadá (CDC, 2009; WHO, 2009). Poco más de la mitad de los pacientes presentó cefalea y dolor osteomuscular generalizado, y poco más de un cuarto presentó náusea o vómito y datos de conjuntivitis. Estas últimas manifestaciones no son frecuentemente reportadas en la serie de casos de Estados Unidos, Canadá o México.

El presente es el primer estudio que caracteriza los casos de influenza tipo A en un contexto de pandemia por un nuevo subtipo viral de origen porcino (H1N1) en Nicaragua. El patrón de transmisión refleja más una diseminación local que de casos importados. Dos momentos epidemiológicos importantes fueron determinados por transmisión de la enfermedad a lo interno de centros escolares. Las manifestaciones clínicas son características de gripe con algunas pocas diferencias clínicas a lo descrito en otros países.

\section{Referencias bibliográficas}

CENTER FOR DISEASES CONTROL (CDC) (2009) "Update: Novel Influenza A (H1N1) virus infections - Worldwide, May 6, 2009”. Morbid Mortal Week Report 58(17):453-458.

FRASER, C.; DONNELLY, C.A.; CAUCHEMEZ, S.; HANAGE, W.P.; VAN KERKHOVE, M.D. \& HOLLINGWORTH, D. (2009) "Pandemic potential of a strain of Influenza A (H1N1): early findings". Science 3421:1557-1561.

WORLD HEALTH ORGANIZATION (WHO). Global alert and response: Influenza $A$ (H1N1) - Update 55. Disponible en: http://www.who.int/csr/don/2009 06 29/en/index. html Consultado: junio, 2009.

NOVEL SWINE-ORIGIN INFLUENZA A (H1N1) VIRUS INVESTIGATION TEAM (2009) "Emergence of a novel swine-origin Influenza A (H1N1) in humans". New Engl J Med, 361:1-10.

GORDON, A.; ORTEGA, O.; KUAN, G.; REINGOLD, A.; SABORÍO, S. \& BALMACEDA, A. (2009) 
"Prevalence and seasonality of influenza like-illness in children, Nicaragua, 2005-2007". Emerg Infect Dis 5(3):408-414.

LIANG, M.; LYE, D.C.; CHEN, M.I.; CHOW, A.; KRISHNAN, P. \& SEOW, P. (2009) "New influenza A (H1N1) 2009 in Singapore: the first ten adult imported cases". Singapore Med $J$ 50(6):581-3.

MOSSAD, S.B. (2009) "The resurgence of swine-origin influenza A (H1N1)". Clev Clin J Med 76(6):337-43.

WORLD HEALTH ORGANIZATION (WHO) (2009) "Human infection with new influenza A (H1N1) virus: clinical observations from Mexico and other affected countries, May 2009". Wkly Epidemiol Rec 84:185-189. 